\title{
Environmental enrichment condition does not alter glutamine synthetase activity in the hippocampus and cerebral cortex of Swiss albino mice
}

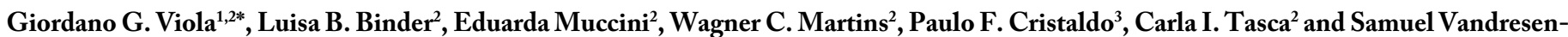 \\ Filho $^{2,4}$ \\ ${ }^{1}$ Programa de Pós-Graduação em Ciências Fisiológicas, Centro de Ciências Biológicas e da Saúde, Universidade Federal do Sergipe, Brazil \\ ${ }^{2}$ Programa de Pós-Graduação em Neurociências, Centro de CiênciasBiológicas, Universidade Federal de Santa Catarina, Florianópolis, Brazil \\ ${ }^{3}$ Laboratório de Interações Ecológicas, Departamento de Ecologia, Centro de Ciências Biológicas e da Saúde, Universidade Federal do Sergipe, Brazil \\ ${ }^{4}$ Departamento de Ciências Básicas em Saúde, Faculdade de Medicina, Universidade Federal de Mato Grosso, Brazil
}

\begin{abstract}
Environment enrichment (EE) promotes morphological changes in astrocytes and gliogenesis, as well an increment in the synapses number of hippocampus. In addition, exposure to $\mathrm{EE}$ is known to increase the astrocytic number and volume in cortical regions. The glutamine synthetase (GS) is an astrocyte enzyme that converts glutamate into glutamine, which play an important role in the glutamate/glutamine cycle. Here, we hypothesized that the GS activity would be increased in the cortex and hippocampus of mice living in EE. For this, mice were assigned randomly in two housing conditions: standard condition (SC) or enriched environment (EE) and the GS activity was evaluated after 9 weeks. Our results showed that EE did not promote any significant change in GS activity in both regions tested. Future studies must focus on the temporal analyses of GS activity after EE conditions as well in other species and/or strains and during distinct age of life in order to understand the factors affecting the GS activity after exposition to EE conditions.
\end{abstract}

\section{Introduction}

Environmental enrichment (EE) is a form of manipulation in which captive animals are exposed to complex conditions through alterations in the physical and social environment [1]. EE manipulation occurs by the introduction of objects (e.g. running wheels, shelters, etc.) with different textures, colors, shapes, sizes, and also by changing their places in the home cage, which lead to enhanced of sensory, cognitive and physical stimulation [2]. It has been demonstrated that EE improve the cognitive capacity of rats [3], mice [4], horses [5] and it also promotes a reduction in the risk of dementia in human [6].

Exposition to EE is known to promote an improvement in the neuroplasticity of several brain areas [1], as well as stimulation of hippocampal response such as morphological changes in both neurons $[7,8]$ and astrocytes [4,9]. In addition, EE is known to improve the neurogenesis [10], gliogenesis[11] and synaptogenesis [12]. Likewise, increase in volume and number of astrocytes have also been reported after EE in cortical regions $[13,14]$. In the visual cortex, the contact between astrocytic processes and synapses increases after EE conditions [15].

Additionally, it has been demonstrated that mice exposed to short periods under EE conditions promote improvement in the glutamartergic pathways in the cortex. The expression level of the postsynaptic density-95 protein (PSD95), the anchoring of the $\mathrm{N}$-methyl-D-aspartate glutamate receptor (NMDA) in postsynaptic membrane, and calmodulin, the downstream of NMDA receptor, are up-regulated after EE [16]. Furthermore, mice subject to 40 days of EE present an increase in the levels of GluR2 and GluR4 (AMPA subunits) in the hippocampus [17]. In this way, a short period of EE promote improvement in the PSD95, Ras and reelin gene expression in hippocampus of NMDAR1-knockout (KO) and suggest that these signal pathways are possibly involving in the beneficial effects of EE on memory improvement in this KO mice [18]. Accordingly, young Wistar rats exposed to EE for three months showed higher hippocampal glutamate and GABA concentrations [19].

Glutamate uptake in astrocytes is currently known to be performed by sodium-dependentglutamatergic transporters, GLT-1 and GLAST. Once inside astrocytes, glutamate may be converted to glutamine in the presence of ammonia by the activity of glutamine synthetase (GS). Glutamine is then transferred to neurons where it can be converted back to glutamate by phosphate-activated glutaminase. It is well documented that GS activity plays a crucial role to maintain glutamate release during increased activity of glutamatergic synapses [20]. Thus, astrocytes play an important role in glutamatergic synapses, including uptake and turnover of glutamate. Considering it, in the present study we tested the hypothesis that GS activity improvedin hippocampus and cortex of animals living under EE conditions.

Correspondence to: Giordano Gubert Viola, Programa de Pós-graduaçãoem Ciências Fisiológicas, Departmento de Fisiologia, Universidade Federal de Sergipe, São Cristóvão, SE - Brasil, Tel: 55-79-2105-6600; E-mail: giorgviola@ gmail.com

Key words: astrocyte, brain, enriched environment, glia, glutamate

Received: September 12, 2015; Accepted: September 28, 2015; Published: September 30, 2015 


\section{Material and methods}

\section{Animals and approval}

Male albino Swiss mice (21 days old) were obtained from Central Animal Facility of Universidade Federal de Santa Catarina. Mice were kept in experimental cages under two different conditions with water and food ad libitum, controlled light/dark photoperiod cycle (12:12 h; lights on at 7:00 a.m.) and room temperature adjusted to $21 \pm 1^{\circ} \mathrm{C}$. All experimental procedures were performed according to the NIH Guide for Care and Use of Laboratory Animals and Brazilian Society for Neuroscience and Behavior (SBNeC). Recommendations for Animal Care and approved by the Ethical Committee of the Universidade Federal de Santa Catarina (UFSC). All efforts were made in order to minimize the number of animals used and their suffering.

\section{Experimental procedure}

Groups composed by 20 albino Swiss mice were randomly exposed in two housing conditions: standard condition (SC; control group) or enriched environment (EE; treatment group). Groups under SC were housing in apparatus of Plexiglas box $(38 \mathrm{~cm} \times 32 \mathrm{~cm} \times 16 \mathrm{~cm})$ containing just sawdust. EE groups were kept in Plexiglas box $(38 \mathrm{~cm}$ x $32 \mathrm{~cm} \mathrm{x} 16 \mathrm{~cm})$ connected to a three-story metal cage $(28 \mathrm{~cm} \mathrm{x} 21$ $\mathrm{cm} \times 50 \mathrm{~cm}$ ) containing sawdust, two running wheels and a variety of objects including wood and plastic objects, nesting material and hiding places, such as tunnels in order to represent eco-ethological expansions for mice including the sense of security and to provide a place where they could avoid open spaces and luminosity, a natural behavior of wild mice. Additional cognitive stimulation regarding the formation of spatial mapping was provided by changing the objects or shifting their positions twice a week in the EE treatment. In both, SC and EE, treatments animals were kept for 63 days ( 9 weeks).

\section{Glutamine sinthetase activity}

Activity of GS enzyme was measured as adapted from Shapiro and Stadtman [21,22] and Stadtman et al. [23] and modified by VandresenFilho et al. [24]. Two groups containing five mice each were killed by decapitaton. Hippocampi and cerebral cortex were rapidly removed and homogenized in imidazole- $\mathrm{HCl}$ buffer $(80 \mathrm{mM}, \mathrm{pH} 7.0)$. The assay mixture contained $80 \mathrm{mM}$ imidazole- $\mathrm{HCl}$ buffer, $30 \mathrm{mM}$ glutamine, 3 $\mathrm{mM} \mathrm{MnCl} 2,30 \mathrm{mM}$ hydroxylamine- $\mathrm{HCl}, 20 \mathrm{mM}$ sodium arsenate, 0.4 $\mathrm{mM}, \mathrm{ADP}$ and $50 \mu \mathrm{l}$ of the tissue homogenate. The reaction stopped after $30 \mathrm{~min}$ at $37^{\circ} \mathrm{C}$ by adding $100 \mu \mathrm{l}$ of a mixture containing $4 / 1 / 0.5 / 6.5$ $(\mathrm{v} / \mathrm{v} / \mathrm{v} / \mathrm{v})$ of $10 \%(\mathrm{w} / \mathrm{v})$ ferric chloride, $24 \%(\mathrm{w} / \mathrm{v})$ trichloroacetic acid, 6 $\mathrm{M} \mathrm{HCl}$ and water. The reaction product, $\gamma$-glutamylhydroxamate, was measured at $540 \mathrm{~nm}$ and converted to the amount of product formed by comparison with a standard curve of $\gamma$-glutamylhydroxamate ranging from 100 to $1000 \mu \mathrm{M}$. The activity of GS enzyme was expressed in unit(s) per milligram of protein in the sample per minute.

\section{Statistical analyses}

Comparison of GS activity on hippocampus and cortex among groups (SC vs. EE) were performed using an unpaired two-tailed Student's $t$ test, with $p<0.05$ as indicative of statistical significance. All data were expressed as means \pm standard error.

\section{Results}

The GS activity measured in the hippocampal homogenates between $\mathrm{SC}$ and EE groups do not present significant differences ( $\mathrm{t} 8=$ $1.281, \mathrm{p}=0.2361$; Figure $1 \mathrm{~A}$ ). In the same way, the GS activity measured

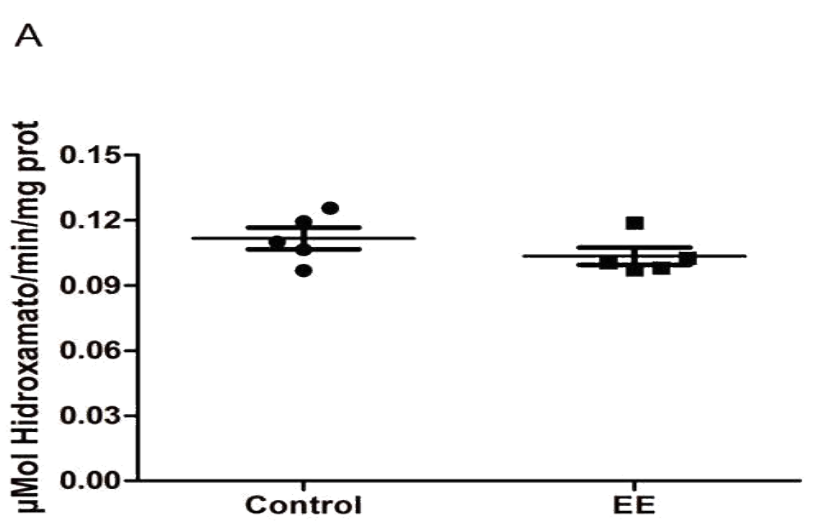

B

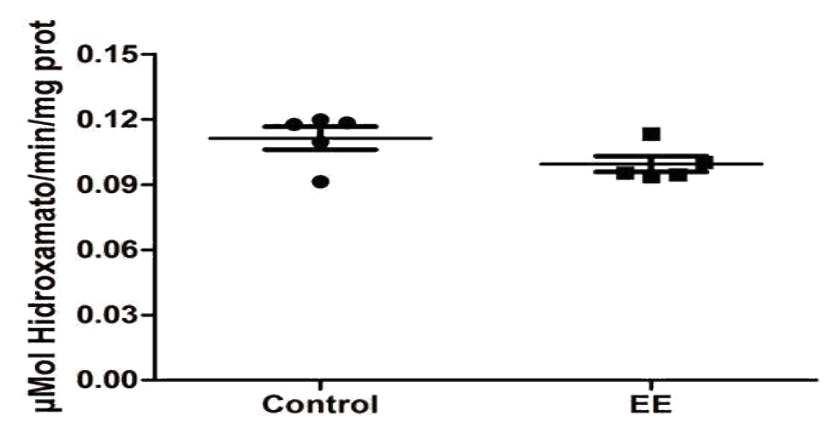

Figure 1. Glutamine synthetase activity in the hippocampus and cerebral cortex regions of Swiss albino mice exposed to standard condition (SC) and enriched environment (EE) conditions. Mice were housed in SC or EE treatments for 9 weeks. After this period, mice were killed and hippocampi (A) and cerebral cortex (B) were removed to evaluate the GS activity. Values represent means \pm S.E. of experiments carried out in triplicates $(n=5)$. Each point represents a specific animal. No significant differences were observed among SC and EE conditions in both hippocampus (A) and cortex (B) regions. (Student's t test).

in the cortical homogenates between $\mathrm{SC}$ and $\mathrm{EE}$ groups do not present significant differences $(\mathrm{t} 8=1.842, \mathrm{p}=0.1028$; Figure $1 \mathrm{~B})$.

\section{Discussion}

Considering the pivotal role of glutamatergic transmission in neural plasticity and the improvement in dendritic complexity [7], synaptogenesis [12], complexity of astrocyte morphology [9] and in gliogenesis [11], we would expect that GS activity might be improved in hippocampus of mice exposed to EE conditions when compared with mice living in control conditions. Furthermore, taking into account the increment in the volume and number of astrocytes in cortical regions after EE $[13,14]$ and the contact between astrocytic processes and synapses increment after exposition to EE conditions [15], an improvement of GS activity in cortex regions of mice exposed to EE conditions when compared with mice living in control conditions was also expected. However, in the present study, our results showed that albino Swiss mice maintained under EE conditions for 9 weeks not presented alteration in the GS activity in both hippocampus and cortex regions. Such results do not allow us to accept the hypothesis proposed in the present study.

Previous studies have been showed that EE housing promotes alterations in the morphology of neurons [7], synaptic elements [12] 
and also astrocytes [9]. Additionally, synaptic elements (e.g. PSD95, synaptophysin, calmodulin) and neurotrophic factors in the regions were improved in animals exposed to EE conditions [16]. Despite such findings, several divergences results can be found in the literature about the effect of animals living under EE conditions; BDNF levels in the hippocampus, for example, have been shown to be increased after EE exposure, but also no changes have been reported [3]. These different effects of EE conditions can be generated by intrinsic responses of animal species or strain used in the experiments as well their age and also by the time to perform the analysis during the protocol [25].

An improvement of gliogenesis in the dentate gyrus in old Swiss albino mice was reported [11]. Additionally, morphological changes in astrocytes of the Stratum Radiatum of CA1 in the hippocampus was observed in CF1 mice [9]. However, Swiss albino mice present different responses to EE conditions when compared with other strains or species: no changes in the neurogenisis [26] while there is an increase in the neurogenesis in dentate gyrus in $\mathrm{BALB} / \mathrm{cByJ}$ mice after $\mathrm{EE}$ housing [27]. The hypo-responsiveness of Swiss albino mice to EE can be one possible explanation for no changes in the GS activity observed in the present study. Further analysis of GS activity in other strains or species is still necessary in order to elucidate such inconsistent results.

Besides above explanations, GS activity also present divergences responses. Wistar rats exposed to forced exercise for 4 weeks showed an increase activity of GS in the hippocampus [28], however, no changes were also observed with the same specie/strain and with the same protocol of forced exercise but for a longer period (12 weeks) [29]. Likewise, Mora-Gallegos et al. [19] showed that young Wistar rats exposed to EE present improve in the glutamate and GABA concentration in hippocampus, however, adult rats of the same strain exposure to the same EE protocol, does not change the concentration of glutamate and GABA. It this view is known that the neuronalastrocyte unit is affected by age in the hippocampus [30]. Here, no changes were observed in the GS activity in the hippocampus of albino Swiss mice under EE conditions after 9 weeks, which can be generated by a transitory effect in the GS activity.

Another suitable explanation behind our results may involve the differential response to corticosterone between GS and glial fibrillary acidic protein (GFAP) [31]. Mc Quaid et al. [32] observed an increase in the aggressive behaviour and higher plasma corticosterone concentrations in CD-1 male mice after exposure to EE condition. In fact, increase in corticosterone concentration has been shown to promote an increment in GFAP expression and calcium wave in hippocampal astrocytes [33]. Therefore, it is suitable to postulate that levels of corticosterone in brain affect the astrocytes morphology and activity in animals maintained in EE. The nitration on the tyrosine residue through a NMDA receptor-mediated cGMP-NO is known to modulate negatively the GS activity [34], which can be another possible explanation for the result found in the present study.

Both regions study here (cortex and hippocampus) are rich in such receptor and $\mathrm{EE}$ condition have been reported to increase the expression levels of PSD-95 and calmodulin in the cortex [16], spine density [12] and also an improvement in the PSD95, Ras and reelin gene expression in hippocampus. Thus, could be that the improvement of synapses [12] and the activation of NMDA receptor [16], both reported after EE exposure, modulating negatively the GS activity.

In summary, our results showed no alteration of GS activity in the hippocampus and cerebral cortex of young male albino Swiss mice exposed to EE conditions after 9 weeks. Future studies must focus on the temporal analyses of GS activity after EE conditions as well in other species and/or strains and during distinct age of life. Such new analyses may provide a better understanding of the participation of astrocytes in the neuroplasticity promoted by environmental changes.

\section{Highlights}

- EE does not alter Glutamine Synthetase activity in hippocampus of Swiss albino mice;

- $\quad$ EE does not alter Glutamine Synthetase activity in cortex of Swiss albino mice;

- $\quad$ Swiss albino mice are hyporesponsive to EE;

- $\quad$ Future studies must focus on the temporal analyses of GS activity after EE conditions.

\section{Acknowledgement}

This work was supported by CAPES-Brasil, CNPq-Brasil and Fundação de Amparo à Pesquisa do Estado de Santa Catarina (FAPESC).

\section{References}

1. Nithianantharajah J, Hannan AJ (2006) Enriched environments, experience-dependen plasticity and disorders of the nervous system. Nat Rev Neurosci 7: 697-709.

2. Girbovan C, Plamondon H (2013) Environment enrichment in female rodents considerations in the effects on behavior and biochemical markers. Behav Brain Res 15: 178-190. [Crossref]

3. Viola GG, Bottom PH, Moreira JD, Ardais AP, Oses JP, et al. (2010) Influence of environmental enrichment on an object recognition task in CF1 mice. Physiol Behav 99: 17-21. [Crossref]

4. Sampedro-Piquero P, De Bartolo P, Petrosini L, Zancada-Menedez C, Arias JL, et al (2014) Astrocytic plasticity as a possible mediator of the cognitive improvements after environmental enrichment in aged rats. Neurobiol Learn Mem 114: 16-25. [Crossref]

5. Lansade L, Valenchin M, Foury A, Neveux C, et al. (2014) Behavioral and Transcriptomic Fingerprints of an Enriched Environment in Horses (Equuscaballus). PLoS One 9: e114384. [Crossref]

6. Then FS, Luppa M, Schroeter ML, Konig HH, Angermeyer MC, et al. (2014) Enriched environment at work and the incidence of dementia: results of the Leipzig longitudinal study of the aged (LEILA 75+). PLoS One 8: e70906. [Crossref]

7. Faherty CJ, Kerley D, Smeyne RJ (2003) A Golgi-Cox morphological analysis of neuronal changes induced by environmental enrichment. Brain Res Dev Brain Res 141 : 55-61. [Crossref]

8. Gelfo F, Bartolo P, Giovine A, Petrosini L, et al. (2009) Layer and regional effects of enrichment on the pyramidal neuron morphology of rats. Neurobiol Learn Mem 91: 353-365. [Crossref]

9. Viola GG, Rodrigues L, Américo JC, Hansel G, Vargas RS, et al. (2009) Morphological changes in hippocampal astrocytes induced by environmental enrichment in mice. Brain Res 1274: 47-54. [Crossref]

10. Kempermann G, Kuhn HG, Gage FH (1997) More hippocampal neurons in adult mice living in enriched environment. Nature 386: 493-495. [Crossref]

11. Diniz DG, Foro CA, Rego CM, Gloria DA, de Oliveira FR, et al. (2010) Environmenta impoverishment and aging alter object recognition, spatial learning, and dentate gyrus astrocytes. Eur J Neurosci 32: 509-519. [Crossref]

12. Moser MB, Trommald M, Anderson P (1994) An increase in dendritic spine density on hippocampal CA1 pyramidal cells following spatial learning in adult rats suggests the formation of new synapses. Proc Natl Acad Sci USA 91: 12673-12675. [Crossref]

13. Szeligo F, Leblond CP (1977) Response of the three main types of glial cells of cortex and corpus callosum in rats handled during suckling or exposed to enriched, control and impoverished environments following weaning. J Comp Neurol 172: 247-263.

14. Sirevaag AM, Greenough WT (1991) Plasticity of GFAP-immunoreactive astrocyte size and number in visual cortex of rats reared in complex environments. Brain Res 540: 273-278. [Crossref] 
15. Jones TA, Greenough WT(1996) Ultrastructural evidence for increased contact between 283 astrocytes and synapses in rats reared in a complex environment. Neurobiol Learn Mem 65: 48-56. 284. [Crossref]

16. Rampon C, Jiang CH, Dong H, Tang YP, Lockhart DJ, et al. (2000) Effects of environmental enrichment on gene expression in the Brain. Proc Nalt Acad Sci USA 97: 12880-12884. [Crossref]

17. Naka F, Narita N, Okado N, Narita M (2005) Modification of AMPA receptor properties following environmental enrichment. Brain Dev 27: 275-278. [Crossref]

18. Li C, Niu W, Jiang CH, Hu Y (2007) Effects of enriched environment on gene expression and signal pathways in cortex of hippocampal CA1 specific NMDAR1 knockout mice. Brain Res Bull 71: 568-577. [Crossref]

19. Mora-Gallegos A, Rojas-Carvajal M, Salas S, Saborío-Arce A, Fomaguera-Trías J, et al. Age-dependent effects of environmental enrichment on spatial memory and neurochemistry. Neurobiol Learn Mem 118: 96-114

20. Tani H, Dulla CG, Farzampour Z, Taylor-Weiner A, Huguenard JR, et al. (2014) A local glutamate-glutamine cycle sustains synaptic excitatory transmitter release. Neuron 81 : 888-900. [Crossref]

21. Loss CM, Binder LB, Muccini E, Martins WC, de Oliveira PA, et al. (2015) Influence of environmental enrichment vs. time-of-day on behavioral repertoire of male Swiss mice. Neurobiol Learn Mem 125: 63-72. [Crossref]

22. Shapiro BM, Stadtman ER (1970) The regulation of glutamine synthesis in microorganisms. Annu Rev Microbiol 24: 501-524.

23. Stadtman ER, Ginsburg A, Ciardi JE, Yeh J, Hennig SB, et al. (1970) Multiple molecular forms of glutamine synthetase produced by enzyme catalyzed adenylation anddeadenylylation reactions. Adv Enzyme Regul 8: 118. [Crossref]

24. Vandresen-Filho S, Martins WC, Bertoldo DB, Mancini G, Herculano BA, et al. (2013) Atorvastatin prevents cell damage via modulation of oxidative stress, glutamate uptake and glutamine synthetase activity in hippocampal slices subjected to oxygen/glucose deprivation. Neurochem Int 62: 948-955. [Crossref]
25. Viola GG, Loss CM (2014) Letter to Editor about: "Physical exercise increases GFAP expression and induces morphological changes in hippocampal astrocytes. Brain Struct Funct 219: 1509-1510.

26. Silva CF, Duarte FS, Lima TC, de Oliveira CL (2011) Effects of social isolation and enriched environment on behavior of adult Swiss mice do not require hippocampal neurogenesis. Behav Brain Res 225: 85-90. [Crossref]

27. Tanti A, Westphal WP, Girault V, Brizard B, Devers S, et al. (2013) Region-Dependent and Stage-Specific Effects of Stress, Environmental Enrichment, and Antidepressant Treatment on Hippocampal Neurogenesis. Hippocampus 23: 797-811. [Crossref]

28. Bernardi C, Tramontina AC, Nardin P, Biasibetti R, Costa AP, et al. (2013) Treadmill exercise induces hippocampal astroglial alterations in rats. Neural Plast: 1-10. [Crossref]

29. Santin K, da Rocha RF, Cechetti F, Quincozes-Santos A, de Souza DF, et al. (2011) Moderate exercise training and chronic caloric restriction modulate redox status in rat hippocampus. Brain Res 1421: 1-10. [Crossref]

30. Soffié M, Hahn K, Terao E, Eclancher F (1999) Behavioural and glial changes in old rats following environmental enrichment. Behav Brain Res 101: 37-49. [Crossref]

31. Laping NJ, Nichols NR, Day JR, Johnson SA, Finch CE (1994) Transcriptional contro of glial fibrillary acidic protein and glutamine synthetase in vivo shows opposite responses to corticosteronein the hippocampus. Endocrinology 135: 1928-1933. [Crossref]

32. McQuaid RJ, Audet MC, Anisman H (2012) Environmental enrichment in male CD-1 mice promotes aggressive behaviors and elevated corticosterone and brain norepinephrine activity in response to a mild stressor. Stress 15: 354-360. [Crossref]

33. Chatterjee S, Sikdar SK (2013) Corticosterone treatment results in enhanced release of peptidergic vesicles in astrocytes via cytoskeletal rearrangements. Glia 61: 2050-2062. [Crossref]

34. Rodrigo R, Felipo V (2007) Control of brain glutamine synthesis by NMDA receptors. Front Biosci 12: 883-890. [Crossref]

Copyright: (C) 2015 Viola GG. This is an open-access article distributed under the terms of the Creative Commons Attribution License, which permits unrestricted use, distribution, and reproduction in any medium, provided the original author and source are credited. 